Gabriel Salazar, Mercaderes, Empresarios y Capitalistas (Chile, Siglo XIX) (Santiago: Edit. Sudamericana 2009), 794 páginas.

\title{
MERCADERES, EMPRESARIOS Y CAPITALISTAS (CHILE, SIGLO XIX) DE GABRIEL SALAZAR
}

\author{
Alfredo Jocelyn-Holt
}

\section{I}

$\mathrm{P}$

aradójicamente son de izquierda y no de derecha los historiadores más interesados en hacer una historia del capitalismo en Chile. Según el reciente libro de Gabriel Salazar, Mercaderes, Empresarios y Capitalistas, esto tendría una explicación. Ocurre que, desde la Independencia, lo que entendemos por institucionalidad política no habría sido más que un Estado dictatorial — creado por Portales - concebido para mantener militarmente el orden, explotar a las clases populares y dedicarnos como país a lo único que el patriciado local sería capaz: constituirse en mero intermediario mercantil, importar y comerciar bienes a cambio de exportar materias primas de menor valor. Portales lo entendió muy bien; Portales era comerciante, el patriciado local también lo fue. Nada, sin embargo, que pueda reconocerse abiertamente porque nos desprestigiaría como nación autónoma.

La tesis, como se puede apreciar, es una carambola perfecta. Niega el potencial local para modernizarnos a no ser que sea promovido por intereses económicos foráneos (palo a los nacionalistas). Resta

Alfredo Jocelyn-Holt. Historiador; D. Phil., Oxford. Profesor de la Universidad de Chile.

Palabras clave: historia general de Chile; historiografía; capitalismo; dependencia; orden portaliano; historia del pueblo.

Estudios Públicos, 121 (verano 2011). 
valor a los pocos empresarios que podrían demostrar algún grado de empuje y capacidad de capitalización (palo a los neoliberales actuales o retrospectivos). Niega cualquier mérito al desarrollo institucional alcanzado salvo haber cumplido tareas puramente disciplinarias y coercitivas (palo a los liberales auténticos). Tacha de mitómana al grueso de la historiografía nacional porque siendo más conservadora que de izquierda, ¿de qué ha servido si no para cegarnos frente a nuestra única y pérfida realidad estancada? (palo a los conservadores).

Un solo poder - el capital extranjero - ha reglado nuestro devenir histórico republicano, afirma Salazar. Siempre hemos sido lo que somos: un país subdesarrollado y dependiente. Fue así durante la Colonia (palo a los colonialistas), siguió siéndolo durante el siglo XIX, y aunque en el XX nos autonomizamos quizá un poco gracias al Estado interventor entre 1938-1973 (guiño a los desarrollistas), qué le vamos hacer, hemos vuelto al modelo estructural desde que la dictadura reciente -obvio que "portaliana" - nos devolvió a la lógica que no ve otra lógica posible (palo al pinochetismo y al concertacionismo, por separado y coludidos en mortal abrazo).

Evidentemente, la tesis es insostenible. Se pega demasiados saltos anacrónicos. Presume continuidades que no pueden ser (la historia registra algo más que inercia estática). Abusa del monocausalismo. Peca de simplista cuando da a entender que los únicos patricios que vale atender son los con plata. Es más, suena "dependentista" en exceso, y eso que el dependentismo como tesis dejó de convencer hace rato ${ }^{1}$. Debe demasiado

${ }^{1}$ Disiente Cristián Barros de esta opinión en su reseña del libro en El Mercurio, 21 febrero 2010, p. E 13. A su juicio, la tesis del libro no sería monocausal ("todo haría pensar que Salazar reedita una versión de la teoría de la dependencia en clave foucaultiana, prestando una atención nostálgica y cómplice a los sujetos marginales, y brindando un villano fácil al martirologio popular. Incluso, una lectura epidérmica podría inducir a tacharlo de monocausal. Nada menos cierto. Salazar ha construido un relato complejo, rico en oposiciones; en suma, dialéctico. No hay causalidades simplistas ni maniqueísmos. De hecho, Mercaderes, Empresarios y Capitalistas... reivindica parcialmente el rol modernizador del capital extranjero"). Yo insistiría en el punto. La dialéctica, aspecto que Barros concede, es por definición monocausalista. Es más, Salazar admite haber sido fuertemente influido por André Günder Frank, creador de la tesis dependentista; fue su alumno y lo reconoce como uno de sus cuatro principales "maestros", siendo los otros Héctor Herrera Cajas, Mario Góngora y Juan Rivano. Para una visión general del capitalismo en Salazar, véanse los siguientes títulos de su autoría: "El Movimiento Teórico sobre Desarrollo y Dependencia en Chile. 1950-1975" en Revista Nueva Historia, Asociación de Historiadores Chilenos en el Reino Unido, University of London, Londres, 1982; Algunos Aspectos Fundamentales del Desarrollo del Capitalismo en Chile (Santiago: 2003); y también su otro libro al respecto, Historia de la Acumulación Capitalista en Chile (Apuntes de Clase), Curso Dictado en el Campo de Prisioneros Politicos Tres Álamos, 1976 (Santiago: 2003). 
a las erradas interpretaciones de Alberto Edwards, Francisco A. Encina y Mario Góngora que se obsesionaron con la figura de Portales, aunque es mérito indiscutible de Salazar — chapeau — haberle agregado este nuevo giro económico al cuento de siempre. Desvaloriza la autonomía de lo político que el marxismo en su versión más heterodoxa (¡cómo olvidar a Gramsci!) terminó por admitir; no todo es economía, no a menos que se quiera uno adscribir a esa fauna neoliberal simplista que materializa todo. Tampoco se conceden cambios, esenciales a veces, en el mismo capitalismo y que explican su capacidad de adaptación y persistencia ${ }^{2}$. En fin, a esta tesis se la puede refutar desde tantos o más ángulos que los múltiples que abre legítimamente a discusión.

Dicho lo anterior, es notable haber escrito un libro de casi 800 páginas (¿quién lo hace en Chile en un solo tomo?); haberle dedicado 34 años a la investigación; haber comprendido directa e indirectamente periodicidades formidables, desde la Colonia a nuestros días; haberles seguido la pista a numerosos comerciantes, sus negocios, nexos coetáneos y generaciones posteriores; haber explicado complejísimas operaciones mercantiles - agotadoramente aburridas, así al menos pueden parecer a algunos lectores - a fin de develar un sistema intrincado, su propósito y blanco.

$\mathrm{Y}$, eso que, alabando este tratamiento titánico de dimensiones no menos monumentales, ni siquiera estaríamos dando cuenta de sus muchos otros méritos más sutiles. Como cuando Salazar pareciera hablar en parábolas; cuando deja a un lado el análisis y simplemente narra; cuando volviendo al pasado pareciera referirse subliminalmente al presente; cuando tipifica y acuña términos; cuando se confirma por lo que es, magistral en su rescate de sujetos en su contexto no sólo real y material, también ideal, filosófico y sociológico. De todos nuestros historiadores, Salazar es el que mejor calza con lo que, en su momento, se denominó y aspiró a ser "historia total”. Por último, ¡qué desafío el que ha legado a los historiadores del capitalismo, no de izquierdas, que se atrevan a recoger el guante! Chapeau de nuevo ${ }^{3}$.

\footnotetext{
${ }^{2}$ Véase por ejemplo el libro de Luis Ortega Martínez, Chile en Ruta al Capitalismo. Cambio, Euforia y Depresión, 1850-1880 (Santiago: 2005). Conste que Luis Ortega es el otro fundador, junto a Salazar, de la Asociación de Historiadores Chilenos en el Reino Unido, y editor de la Revista Nueva Historia, influyente medio de renovación historiográfica en el exilio. De más está señalar que las posturas entre Ortega y Salazar en este sentido no son coincidentes.

${ }^{3}$ Hasta aquí el texto reproducido de la reseña del libro titulada "Una Obra Mayor" que hiciera para La Tercera del 29 de noviembre de 2009, p. 91, salvo las notas al pie agregadas y uno que otro ajuste para esta versión. La ampliación restante que sigue a continuación es inédita.
} 
Con esta publicación Salazar recapitula una obra maciza, imponente, que abarca una variedad de ángulos y aciertos. Ya antes, su primer libro (Labradores, Peones y Proletarios de 1986, entre los hitos historiográficos chilenos más sobresalientes de los últimos treinta años), al centrar su atención en sectores populares silenciados - "masas" marginales a la hacienda, a las ciudades y focos industriales-, propinó un notable doble golpe revisionista. Contra la historiografía clásica porque las miradas políticas "desde arriba" ocultaban una historia más propiamente histórica-representativa, la de un pueblo sufrido y solidario "entre sí" al que se le expropia y exilia del agro tradicional, debiendo vagar tierras e ingeniárselas como puede. Contra también de la vieja escuela sociológica marxista (v. gr. Julio César Jobet, Hernán Ramírez Necochea), no menos prejuiciosa y verticalista, según Salazar, interesada en destacar únicamente al proletariado urbano industrial en desmedro de otros desposeídos. Posteriores trabajos suyos han explicitado, incluso, lo que él percibe como un "proyecto político" auténticamente popular, auto-gestual que, si bien ha sido castigado una y otra vez por las hegemonías dominantes impuestas, se mantiene todavía vivo en sus costumbres, cultura, memoria testimonial, reivindicaciones y praxis rebelde. Justamente, el meollo de su indagación, o mejor dicho, de su rescate histórico.

Lo último, bastante más ambicioso que una mera evocación de un pasado de atropellos, desplazamientos y postergaciones. Al contrario, Salazar a lo que aspira es a elaborar una "Ciencia Histórica Popular" que — como vuelve a reiterar en este nuevo libro - "traiga a la luz todas las fealdades ocultas, todos los fantasmas intersticiales de nuestro pasado y nuestro presente, a fin de que la ciudadanía pueda tener una conciencia histórica más limpia y una memoria cultural más llena de verdad" (p. 12). Otro de sus propósitos es que esta "ciencia del pueblo", en oposición dialéctica a la presión contraria por "alienar" a los grupos desposeídos, rescate y devuelva su "compulsión humanizante" al mundo subalterno, en el fondo, su historicidad intrínseca. De ahí su prolífica obra (una docena de libros en las últimas tres décadas) y las numerosas coincidencias con un conjunto de otros historiadores que se autodenominan la "Nueva Historia Social" (Armando de Ramón, Julio Pinto, María Angélica Illanes, Mario Garcés, Pablo Artaza y otros) es- 
parcidos en distintas instituciones académicas y ONG (organizaciones no gubernamentales) en nuestro atomizado espectro universitario. No una escuela "salazarina" propiamente tal, aunque Salazar, por cierto, es su indiscutible punta de lanza en cuanto a producción, impacto de cátedra y visibilidad pública. Digamos que, más bien, una perspectiva crítica compartida, que se ha expresado en algunas obras colectivas, manifiestos, y con una considerable llegada a estudiantes de pedagogía en historia, muchos de cuyos trabajos de título y grado se orientan en esa dirección ${ }^{4}$.

¿Una "nueva historia" como, a menudo, se le tilda? Pienso que no por varias razones. Salvo Salazar, quien dispone de estudios formales en filosofía y sociología, amén de intereses profundos en historia económica que datan de antes de su tesis doctoral en Inglaterra en la Universidad de Hull (1984), ninguno de los demás exponentes de esta corriente historiográfica posee una predisposición teórica igual de sólida o cultivada. En eso Salazar pertenecería, más bien, a una generación anterior de cuño estructuralista. Fue ayudante de investigación de Mario Góngora para su trabajo Origen de los Inquilinos de Chile Central (1960), y claramente su tesis doctoral (Labradores, Peones y Proletarios) debe mucho a la variante analítica británica asociada a Past \& Present, influyente revista, la versión sajona de los Annales franceses y que, desde los años 1950, renovara los estudios sociales en Gran Bretaña, contando entre sus filas a investigadores de la talla y prestigio de Lawrence Stone, Eric Hobsbawm, y E. P. Thompson ${ }^{5}$. Este último, un modelo en varios sentidos. Desde luego, se ha dicho muchas veces que Salazar es su versión o equivalente chileno; las conexiones temáticas y temporales entre Labradores, Peones y Proletarios y The Making of the English Working Class (1963), el clásico texto de Thompson, son evidentes. También, el hecho de que ambos no hayan renegado enteramente de la "tradición marxista", no al menos para efectos analíticos,

${ }^{4}$ Sobre la obra y propuesta de Salazar, véanse Luis Moulian Emparanza, Gabriel Salazar: 6 Asedios a la Historia. La Historia desde Abajo (Santiago: 1999); Sofía Correa Sutil, "Historiografía Chilena de Fin de Siglo" en Revista Chilena de Humanidades, Facultad de Filosofía y Humanidades, Universidad de Chile, № 21, Santiago, 2001, pp. 47 ss.

5 Sobre esta escuela, consúltese Jim Sharpe, "Historia desde Abajo", en Peter Burke (editor), Formas de Hacer Historia (Madrid: 1994 [1991]); José Andrés-Gallego, Recreación del Humanismo desde la Historia (Madrid: 1994); Gertrude Himmelfarb, The New History and the Old (Cambridge, Massachusetts: 1987), especialmente el capítulo 4. 
aun cuando su propio distanciamiento de la vieja ortodoxia de izquierda procomunista, lo que suele denominarse "Old Left" en el mundo angloparlante, es muy anterior a su exilio en Europa; recordemos que Salazar fue militante del MIR en los años $1970^{6}$.

En efecto, no debiera exagerarse esta supuesta única veta teórica, la estructuralista. Ideológicamente hablando, Salazar responde a una trayectoria complejísima con variadísimos componentes tanto externos como locales que hacen de él un caso muy singular. Desde luego, por tradición familiar desciende de un tronco fuertemente católicoconservador; Salazar ha contado, muchas veces, que en su casa paterna se leía el Diario Ilustrado y que en la elección de 1964 votó por Frei ${ }^{7}$. Hizo clases en el Colegio de San Ignacio y en la Universidad Católica. Su militancia política más radicalizada es relativamente tardía en comparación con la de muchos de sus contemporáneos generacionales. Es más, últimamente, le ha dado por destacar a figuras socialcristianas y por desempolvar cierto corporativismo atávico, algo añejo - los cabildos y fueros coloniales en tanto depositarios de la "democracia de los pueblos"-, temas que hasta ahora sólo parecían preocupar a historiadores de veta ultraconservadora, seguidores de Jaime Eyzaguirre y/o historiadores del derecho, uno que otro abiertamente franquista ${ }^{8}$. Por último, habría que resaltar una línea aun más profunda y persistente: cierta impronta historicista diltheyana, la insistencia aquella que sostiene que los sujetos históricos son clave y que para efectos de entenderlos hay que hacer una historia "desde dentro" conforme a la lógica propia del mismo sujeto en cuestión”. Este último, aspecto muy marcado, sos-

${ }^{6}$ María Angélica Illanes, a propósito de la Historia Contemporánea de Chile (1999-2002) en cinco tomos, escritos en colaboración con Julio Pinto, ha calificado la perspectiva ideológica de Salazar como "marxismo disidente" toda vez que estaría consciente del peligro "del entronizamiento en el poder de una clase que, a nombre de los trabajadores, se encargaría de hacer la Transición (revolucionaria)"; María Angélica Illanes, "La Nueva Historia de Chile", en Cuadernos de Historia, No 19, Universidad de Chile, Facultad de Filosofía y Humanidades, Departamento de Ciencias Históricas, 1999, p. 266.

${ }^{7}$ Sobre el entorno familiar de Salazar, véase la autobiografía de su padre, Benito Salazar Orellana, Memorias de un Peón-Gañán (1892-1984) (Santiago: 2008).

${ }^{8}$ Cf. Gabriel Salazar, "La Gesta Profética de Fernando Vives, S.J., y Alberto Hurtado, S.J.: Entre la Espada Teológica y la Justicia Social" en CED, Patriotas y Ciudadanos (Santiago, 2003), pp. 125-199; y Construcción de Estado en Chile (1800-1837). Democracia de los "Pueblos", Militarismo Ciudadano, Golpismo Oligárquico (Santiago: 2005).

${ }^{9}$ Véase, por ejemplo, su colección de reflexiones teóricas, La Historia desde Abajo y desde Dentro (Santiago: Facultad de Artes, Universidad de Chile, 2003). 
pecho que debido, no poco, a la influencia ejercida por Mario Góngora quien, dicho de paso, también tuvo un recorrido ideológico curioso. Una diáspora intelectual la de Góngora, a primera vista accidentada - fue filofalangista, comunista, apoyó y luego renegó de la dictadura militar, hasta terminar siendo un integrista católico furiosamente crítico del neoliberalismo - si no fuera que Góngora no cejó ni varió nunca de su único norte o común denominador que suele devolverlo siempre a cierta consistencia ideológica inamovible: su constante crítica y rechazo, a lo largo de toda su vida de estudioso, para con el liberalismo y sus distintas variantes. Salazar tiene mucho de esa misma tenacidad firme, anti-ilustrada, anti-dieciochesca, en el fondo una suerte de romanticismo incondicional anti-moderno que también se percibe en una persona dura y recalcitrante como Góngora, su antiguo maestro.

En lo que respecta al método de trabajo que emplea, el rastreo exhaustivo de fuentes archivísticas, en sí, no es particularmente novedoso. En eso Salazar se entronca claramente con la vieja tradición positivista decimonónica aunque con dos variantes que cabría destacar. Por un lado, rescata el actuar de sujetos raramente estudiados, lo que antiguamente se denominaba "bajo pueblo", desde fuentes judiciales por ejemplo; y, por el otro, no menos importante, suele recurrir a presentaciones o cuadros emblemáticos, con gran destreza narrativa, que lo aproximan a la escuela de las mentalidades. Un tratamiento, en ese sentido, bastante original de fuentes, frecuentemente con alcances más metafóricos que literales a modo de viñetas ilustrativas capaces de retratar momentos y constantes históricos de manera dramática, ocasionalmente de índole coral, versión brechtiana. Aciertos que uno no está acostumbrado a ver a partir de evidencia positiva (salvo de la mano de esa notable excepción que siempre fue Vicuña Mackenna), dado nuestro sesgo positivista exageradamente ponderado, aséptico y árido, legado de Barros Arana. Su máxima expresión: el notable ensayo "Ser Niño Huacho en la Historia de Chile", pieza obligada en cualquiera antología de historiografía chilena ${ }^{10}$. También, en este nuevo libro, el capítulo primero: "Peones, mercaderes y dictadores: Entierro y desentierro del tesoro mercantil de Juan Antonio Fresno (Santiago de Chile, 1772-1837)".

10 "Ser Niño Huacho en la Historia de Chile. Siglo XIX", revista Proposiciones, Sur Profesionales, $N^{\circ} 19$, Santiago, 1990, pp. 55-83; hay edición en libro publicado el 2006. 
Salazar es también conocido por un "estilo" de razonamiento muy suyo, tanto escrito como oral ${ }^{11}$. Exposiciones largas y tendidas, brillantes diría, y con efectos indiscutiblemente carismáticos, que recuerdan cierto asambleísmo muy de los años 60 y 70. De ahí, quizá, con algún grado de populismo, aunque esto último sea, ante todo, un efecto discursivo, cifrado en las "masas", el actor épico protagónico, depositario de una historicidad cómplice, de "compañero" a "compañero" con el público, que ningún otro sujeto puede arrebatarle, no al menos, mientras Salazar habla. Nunca de manera insultante o frontal respecto al supuesto contrincante que comparte la mesa; por lo general, más grave y solemne que irónico; tampoco agrio o resentido aun en las ocasiones en que los motivos pudieran sobrarle (Salazar lo pasó muy mal durante la dictadura). Por el contrario, yo diría que es hasta desapegado, como suponiendo a priori que a su discurso se le acepta o no, se comparten sus lógicas o simplemente se está en otra parada y punto. Para nada engreído, engolado, soberbio o burdamente demagógico, sino más bien, como por sobre las circunstancias; como si la Historia, "su historia", hablara a través suyo y por encima del resto. El efecto, obviamente, es un tanto oracular, mesiánico e iluminado y, cuando le resulta, es porque invariablemente así es como el público que lo escucha quiere que sea. No deja de ser impresionante, a veces, simplemente presenciar la sintonía que se produce entre el público y Salazar. De manera más elegante y sobria que histriónica, él es todo un personaje, ciertamente, un orador de primer nivel.

Cuánto de esto se presta para mistificaciones es curiosamente una pregunta con que no se le encara, y eso que su "estilo" da como para pensarlo. La distancia y admiración que genera, quizá, tiende a absolverlo; también, el grado de convicción y solvencia ética con que expone sus puntos de vista. Con todo, algunos argumentos que esgrime son insostenibles. Lo afirmábamos anteriormente al reseñar la tesis principal de este nuevo libro. Ocurre lo mismo cuando argumenta que habría existido un período, un illo tempore indefinido, en que campesinos

${ }^{11}$ Salazar es invitado frecuente de foros, mesas redondas, e intervenciones en seminarios, a las que se me suele también convidar para que nos enfrentemos -él tomando el partido por los "de abajo" y, yo, supuestamente, el de los "de arriba" - lo cual, sin embargo, rara vez ocurre, y cuando llega a producirse, es sin sangre. El segundo semestre de 2002, ofrecimos conjuntamente un curso de formación general para estudiantes de pregrado de la Universidad de Chile titulado "Memoria Social, Historia Oficial: Conflictos en Chile", que tuvo más de cuatrocientos alumnos inscritos. 
autónomos ("labradores") vivían con holgura produciendo un excedente significativo, hasta que se crean las haciendas. Estas últimas les arrebatan sus pequeñas propiedades productivas y el otrora "labrador" autosuficiente se vuelve inquilino o vagabundo, comienza a "rodar" tierras o convertirse en un peón-gañán sin Dios ni ley ${ }^{12}$. Una suerte de caída fatal del paraíso convertido en utopía pretérita; en el fondo, como todas las utopías pretéritas, al decir de Karl Mannheim, útiles para terminar confeccionando y esgrimiendo un argumento ultra-conservador. Operación a la que, de nuevo, vuelve Salazar cuando da a entender que existiría un sustrato inmemorial, un sentir soberano popular, de raíces medievales y forales, que habría operado en los cabildos coloniales, manteniéndose después de la Independencia a través de un anhelo latente por una "democracia de los pueblos"13. ¿Una "democracia" y una "soberanía" antes y después de que la idea nos llegara de la Revolución Francesa y se le condicionara mediante el liberalismo republicano? En efecto, eso precisamente es lo que Salazar está tratando de diluir y reemplazar por esta otra interpretación. ¿Convincente? Yo, al menos, pienso que no. En ninguno de los casos provee Salazar suficiente prueba al respecto como para desbancar las tesis clásicas, por lo mismo, todavía válidas. Es más, suenan efectivamente a mistificaciones retrospectivas, aunque eso no debiera extrañarnos; los mejores historiadores suelen incurrir, consciente o inconscientemente, en ese tipo de hipérboles.

\section{III}

Volviendo a este nuevo texto que nos ofrece, Mercaderes, Empresarios y Capitalistas, ¿por qué Salazar, de repente, cruza la trinchera que él mismo ha cavado y sienta sus reales justo en medio del campo enemigo? Su fuerte historicismo, hasta ahora, lo llevaba a asumir sólo aquellos temas y sujetos por los que tenía empatía (Einfühlung) social, la única manera - “desde dentro" del fenómeno- que le permitiría llegar a comprender (Verstehen). Mi impresión es que ese ángulo Salazar,

${ }^{12}$ Por cierto esta tesis pretende ser una falsificación y alternativa a la clásica tesis de Mario Góngora en Origen de los Inquilinos de Chile Central (1960), libro en que él mismo, repito, fuera ayudante de investigación. Sobre mi propia refutación a Salazar en este punto, véase Alfredo Jocelyn-Holt Letelier, Historia General de Chile. 3. Amos, Señores y Patricios (Santiago: 2004), capítulo IV, nota 29, pp. 128-129, 244.

${ }^{13}$ Véase Construcción de Estado en Chile... (2005), capítulos II y III. 
hace rato, lo agotó. Por mucho que sostenga y crea que es el pueblo el único sujeto auténticamente histórico, después de un rato, el argumento, también la evidencia, comienzan a dar vueltas en banda, se tornan reiterativos de más, y como que sus lectores y oyentes, incluso, pueden hasta adivinar el cuento de antemano. La "Señora Peta", con sus cuatro vacas, su puesto en la feria libre, su ramada convertida en chingana en los extramuros de la ciudad o aldea, con sus siete hijos de cuatro o más gañanes distintos que van y vienen, sus hijas que caen en la prostitución, o ella misma, cambiando de rubro por enésima vez para seguir sobreviviendo ("Ña Peta" es por sobre todo "empresaria", "microempresaria" según el lenguaje un tanto anacrónico al que, a menudo, recurre Salazar), y así, una y otra vez el mismo asunto, tiene un límite. Obviamente estoy exagerando, caricaturizando el argumento, pero no el sentido general, la recurrencia ni tampoco el universo finito, limitado, de posibilidades que abarcan y ofrecen también los archivos judiciales, policiales, etc., en que se basa Salazar y que dan cuenta de las "Ña Petas" de este mundo. Análogamente, El Chacal de Nahueltoro pinta una realidad dramática, tremenda, hasta convertir dicha existencia y su reproducción en obra maestra, pero hasta Miguel Littin se dio cuenta que eso no daba para más secuelas. Un Chacal de Nahueltoro versión II, III y $I V$... son inconcebibles. Pasa lo mismo con el "Canto Nuevo"; llegado un punto, aunque nos encante oír la misma balada, el repertorio, la ambientación, las peñas, y el mismo vinito o chacolí de siempre conducen, a la larga, más temprano que tarde, a un callejón temático sin salida. De repente, ya no es tan "nuevo", ay sí sí sí / aay sí sí sí, es el mismo canto, el canto de todos, que es mi mismo canto... Quizá la poesía lo soporte. En el caso de la historia, sin embargo, ésta se termina por convertir en letanía y lamentación autoconmiserativa, más poesía y épica que realidad historiable. De la mano de Salazar — concedo - en bastante más que eso, pero el peligro es real, incluso en un brillante maestro como él.

Por eso, el giro que viene haciendo, de un tiempo a esta parte, es tan lúcido y acertado. Salazar toma el toro por las astas y opta curiosa y paradójicamente por hacer una historia más de corte convencional. Ya ha postulado la historia de "su pueblo", lo ha hecho hablar, le ha recobrado su noble e indiscutible dignidad, ahora viene una segunda gran arremetida frontal contra la historia oficial y tradicional. La historia oculta, esta vez, develando el supuesto retrato verdadero de "Dorian Gray", el que guardamos (me incluyo entre los historiadores aludidos) 
en el sótano, como gráficamente sostiene en el "Prefacio" a este nuevo volumen.

La construcción (dictatorial) del célebre "orden portaliano" (1829-1860) engendró la más nutrida galería de héroes y hombres ejemplares que haya tenido la historia de Chile: los que, alineados como generación fundadora, han permanecido rampantes y apolíneos, por más de un siglo y medio, en el partenón histórico de la nación. En un gesto inmortal por la obra que legaron — para siempre - a todos los chilenos [...].

Al considerar ese conjunto desde lejos — que recorta en el horizonte como un Arco de Triunfo- no aparenta ser menos que el pórtico de entrada a la historia oficial de Chile. Pues alude y recuerda el origen esencial, solemne, del "alma política" de la nación. El que define su identidad de una vez y para siempre. Contra todo. Contra el avance agreste y tumultuoso de la historia cotidiana y la insolencia de los que traicionan, subversivamente, su "alma nacional" [...]. Por eso, el "origen" del orden portaliano ha renacido y renace como el Ave Fénix, una y otra vez, siempre como "origen", nunca como "fin" [...].

La repetida esencialización (o monumentalización) de ese "origen" - la que puede rastrearse en la gráfica de los textos escolares, en la cartografía estatuaria de cada Alameda, en la señalética callejera de cada ciudad - plantea, sin embargo, algunas dudas. Problemas de no poco fondo, ya que, al monumentalizar el "origen" del orden portaliano, deteniendo el tiempo en la fase constructiva 1829-1860, se anula el proceso histórico posterior. No se asume, por ejemplo, su vida adulta, su madurez. Tampoco su envejecimiento. Ni su esclerotización y muerte. Esencializar - embelleciendo - el origen, equivale a deshistorizar el conjunto, y a esconder el retrato realmente histórico de Dorian Gray, con todos sus cambios, deformaciones y fealdades. A fin de cuentas, monumentalizar el "nacimiento" de un determinado orden social produce, ipso facto, el ocultamiento de su "muerte" histórica, si la tuvo. Y eso puede ser efecto del triunfalismo ingenuo de los vencedores - con la complicidad ingenua de los vencidos-, o de su maquiavelismo político para ocultar las fealdades reales producidas por su triunfo (pp. 7-8).

Podríamos detenernos largamente en algunos alcances y estrategias deconstructivas con que Salazar pretende llevar a cabo su actual propósito de demolición en este libro. Me llama la atención desde luego que acepte, de plano, la existencia del supuesto "orden portaliano". Por eso se propone contarnos la degradación vital y fin o muerte de este or- 
den de cosas, sin reparar en lo obvio, que dicho "orden portaliano" no es más que un constructo historiográfico posterior - fundamentalmente de Edwards Vives, vulgarizado magistralmente por Encina y otros de bastante menor calibre- $-\mathrm{y}$, por tanto, se puede estar cayendo en la misma trampa, en las mismas lógicas, que pretenden denunciarse. El contraargumento, pues, que invalidaría el esfuerzo de Salazar ha sido planteado ya varias veces, pero no es ésta la oportunidad de volver a dicho fascinante debate ${ }^{14}$. Lo que importa resaltar, en esta ocasión, es que nuestro autor se adentra, de este modo, justamente en la supuesta lógica vertebral de la historia de Chile. Mario Góngora, como es bien sabido, afirmó ya una vez que ésta, la tesis de Edwards, es la principal tesis interpretativa de nuestro pasado republicano ${ }^{15}$; y por lo visto, Salazar, otrora fiel discípulo de Góngora, se ha creído el cuento para efectos de dilucidar el camino que lo conducirá, también supuestamente, a escribir su eventual epitafio. Vale el propósito, aunque dudo que le resulte. Una cosa es enterrar un muerto de verdad, otra muy distinta es sepultar un fantasma.

Con todo, lo que me interesa destacar es el giro que, aquí, Salazar ha dado. En el fondo, Salazar se ha tirado al río, y traiga o no agua éste, piensa nadar mucho más con la corriente que lo que ha estado, hasta ahora, dispuesto a reconocer. Su propósito desmitificador, por tanto, es relativo, nada muy novedoso. De hecho, en varias otras publicaciones anteriores - en Violencia Política Popular en las Grandes Alamedas: Santiago de Chile, 1947-1987 (Una Perspectiva Histórico Popular) (1990) por de pronto - aceptó también la terminología y periodificación "portaliana", cuestión que se le hizo ver en su momento, pero, evidentemente, ha querido seguir insistiendo. Si seguimos con cuidado lo que dice literalmente en su notable prefacio a este nuevo libro, el mensaje es claro. Él asume la línea argumental convencional, con la salvedad, a lo sumo, que nos va a llevar al mismo edificio, pero conduciéndonos detrás de bambalinas, a sus sótanos y buhardillas, hasta que encontremos el retrato fidedigno que registra la cara oculta. De ahí, también, que en otras publicaciones recientes - la producción de Salazar estos últimos años es prodigiosa - se haya adentrado en aspectos

${ }^{14}$ Cf. Alfredo Jocelyn-Holt Letelier, El Peso de la Noche. Nuestra Frágil Fortaleza Histórica (Buenos Aires: 1997).

${ }^{15}$ Mario Góngora, Ensayo Histórico sobre la Noción de Estado en Chile en los Siglos XIX y XX (Santiago: 1981), p. 13. 
y figuras que, en otros momentos, insisto, habría desdeñado de plano. En Construcción de Estado en Chile (1760-1860): Democracia de "Los Pueblos" Militarismo Ciudadano Golpismo Oligárquico (2005), se hace cargo de la "construcción de Estado", cuando antes, lo que le interesaba era preferentemente la sociedad civil; enfoca su atención en los militares (concedo que "pipiolos") y en figuras específicas — Ramón Freire- cuando antes sus análisis eran fundamentalmente estructurales, ajenos al papel del sujeto individual, no colectivo, en la historia. Y, por último, en su libro aún más reciente que el que estamos reseñando -Del Poder Constituyente de Asalariados e Intelectuales (Chile, Siglos XX y XXI) (2009) — se adentra nada menos que en ángulos jurídicos, es decir en la superestructura misma. Obviamente todo esto obedece a una lógica.

Mi impresión es que responde nada más y nada menos que a confeccionar una "historia general" del Chile contemporáneo, una línea interpretativa, argumental, de largo aliento, de acuerdo a un viejo y probado género que, en Chile, amén de cultores del género, convoca y congrega lectores, actuales y futuros. Si ése es el caso, Salazar no se equivoca. Intentos similares - los de Barros Arana y Encina por nombrar los más destacados y clásicos en nuestra época republicana- han sido clave para ordenar y difundir la historia, a nivel ilustrado, erudito y también general. Cuestión que no se logra escribiendo monografías puntuales, por muy meritorias que sean, si es que lo son. Reitero, Salazar da en el clavo.

El punto es que esta opción le acarrea una insalvable contradicción. Porque, si al final lo que verdaderamente cuentan son estos grandes frescos panorámicos en que volvemos necesariamente a los mismos temas, a las mismas tesis historiográficas de siempre (al mismo cuento "portaliano"), a los mismos personajes, a la misma estructura de poder elitario, a la misma oligarquía y estatuaria todavía en pie en las grandes Alamedas de Chile, ¿en qué queda ese otro proyecto anterior de Salazar? ¿El de los sujetos populares que asaltan la calle y arremeten contra el orden institucional establecido (Violencia Política Popular en las Grandes Alamedas: Santiago de Chile, 1947-1987 (Una Perspectiva Histórico Popular) (1990), el de los microempresarios que trabajan en los márgenes del orden económico (Ferias Libres: Espacio Residual de Soberanía Ciudadana (Reivindicación Histórica), 2003), el de la sociedad civil (La Sociedad Civil Popular del Poniente y Sur de Rancagua, 2003), en fin, la 
historia "desde abajo" y "desde dentro"? ¿Es que no se puede hacer una "historia general" a partir de estos otros sujetos, de esta otra dimensión popular? ${ }^{16}$ ¿En qué quedó su proyecto de una Ciencia Histórica Popular? ¿Es que no es posible una "nueva historia" conforme a estos otros derroteros teóricos, alternativos al mundo político y superestructural?

Personalmente, me inclino por pensar que no lo es, y de eso se ha dado cuenta Salazar quien ha terminado por darles la razón a los viejos parámetros historiográficos y a las viejas coordenadas políticas. Por cierto, nuestro autor no lo va a reconocer. De hecho, plantea esta nueva estrategia, en este volumen, orillando el asunto. Se va por el lado económico y pone el acento en el capital extranjero y sus agentes, a lo sumo en el carácter mediador de los sujetos elitarios tradicionales. Los terratenientes, según Salazar, no logran réditos económicos tan altos como los mercaderes, ergo, a la larga, no valen, no "pesan". Estrategia que le permite, a fin de cuentas, ningunearlos. Una vez más, se resiste a aceptar su papel real, político, que explica por qué son tan protagónicos a lo largo del siglo XIX y buena parte del XX. No se hace tampoco cargo del colchón rural que es el que le da potencia más social y eventualmente electoral y política, que económica al Chile oligárquico tradicional. Por el contrario, opta por adentrarse en la minucia contable, en el va y viene del capital mercantil, materia que es de enorme interés para economistas, historiadores económicos, pero que uno se pregunta ¿qué tan crucial si lo político es lo que termina dando sustento, gravitación y solvencia social a sociedades todavía jerárquicas y premodernas, no enteramente capitalistas? Por último, en su afán por no hacerse cargo derechamente del mundo político, pasa por alto la larga bibliografía historiográfica que insiste en que la elite chilena tradicional es siempre una sola, altamente endogámica y oligárquica, no se divide como en otros lugares de Latinoamérica entre productores y exportadores; y, es más, desde muy atrás, desde la Colonia, tiende a diversificar sus intereses, pero siempre en aras de obtener influencia y peso político ${ }^{17}$.

${ }^{16}$ Sergio Villalobos Rivera, autor de una Historia del Pueblo Chileno, multivolumen, que no pasó más allá del siglo XVII y eso que pretendía llegar a nuestros días, terminó por abandonar su proyecto; según sus propias palabras, a modo de excusa, porque "estas obras demasiado grandes no tienen éxito ahora". Cf. Óscar Contardo, "Sergio Villalobos: Hoy los historiadores no tenemos ninguna importancia", entrevista en El Mercurio, 22 de mayo, 2007.

${ }^{17}$ Una línea argumentativa que, de hecho, proviene, una vez más, de las investigaciones clásicas de Mario Góngora que se remontan a una primera época, a los orígenes 
Está por verse cómo va a resolver el entuerto. Salazar es infatigable, está produciendo a un ritmo extraordinario, y, por lo visto, no ha perdido ingenio, inventiva, ni sus magníficas antenas. Un historiador tan provocador, además, augura una vigencia a sus argumentaciones para buen rato. Por tanto, aunque sea desde la trinchera del frente, chapeau igual.

mismos de la elite terrateniente tradicional, de ahí su carácter estructural y persistente. Sostienen la unidad de la elite tradicional: Mario Góngora en Encomenderos y Estancieros: Estudios acerca de la Constitución Social Aristocrática de Chile después de la Conquista, 1580-1680 (Santiago: 1971); del mismo autor, "Urban Social Stratification in Colonial Chile" en Hispanic American Historical Review, 55, 3, pp. 421-448, August 1975; Arnold J. Bauer, Chilean Rural Society from the Spanish Conquest to 1930 (Cambridge: 1975), hay trad. La Sociedad Rural Chilena. Desde la Conquista Española a Nuestros Días (Santiago: 1994); Luis Barros y Ximena Vergara, El Modo de Ser Aristocrático: El Caso de la Oligarquía Chilena hacia 1900 (Santiago: 1978); José Bengoa, "Una Hacienda a Fines de Siglo: Las Casas de Quilpué”, Proposiciones №19, 1990; Sofía Correa Sutil, Con las Riendas del Poder. La Derecha Chilena en el Siglo XX (Santiago: 2004); Alfredo Jocelyn-Holt Letelier, La Independencia de Chile. Tradición, Modernización y Mito (Madrid: 1992); Henry Kirsch, Industrial Development in a Traditional Society. The Conflict of Entrepreneurship and Modernization in Chile (Gainsville: 1977); Ricardo Lagos Escobar, La Concentración del Poder Económico. Su Teoría. Realidad Chilena (Santiago: 1965); Thomas F. O'Brien, Jr., The Nitrate Industry and Chile's Crucial Transition: 1870-1891 (New York: 1982); María Rosaria Stabili, El Sentimiento Aristocrático. Elites Chilenas frente al Espejo (1860-1960) (Santiago: 2003); Maurice Zeitlin y Richard Ratcliff, Landlords and Capitalists. The Dominant Class of Chile (New Jersey: 1988). 